\author{
Sebastian Spring \\ Institute of Aerospace Thermodynamics (ITLR), \\ University of Stuttgart, \\ Pfaffenwaldring 31 , \\ Stuttgart 70569, Germany \\ e-mail: sebastian.spring@itlr.uni-stuttgart.de \\ Yunfei Xing \\ Key Laboratory of High Temperature \\ Gas Dynamics, \\ Institute of Mechanics, \\ Chinese Academy of Sciences, \\ Beijing 100190, China \\ Bernhard Weigand \\ Institute of Aerospace Thermodynamics (ITLR), \\ University of Stuttgart, \\ Pfaffenwaldring 31 , \\ Stuttgart 70569, Germany
}

\section{An Experimental and Numerical Study of Heat Transfer From Arrays of Impinging Jets With Surface Ribs}

\begin{abstract}
A combined experimental and numerical investigation of the heat transfer characteristics within arrays of impinging jets with rib-roughened surfaces is presented. Two configurations are considered: One with an inline arrangement of jets and ribs oriented perpendicular to the direction of cross-flow and one with a staggered arrangement of jets and broken ribs aligned with the direction of cross-flow. For both cases, the jet Reynolds number is 35,000, the separation distance measures $H / D=3$, the spent air is routed through one exit contributing to the maximum cross-flow condition, and the rib height and width is both $1 \mathrm{D}$. The experiments are carried out in perspex models using the transient liquid crystal method. Local jet temperatures are measured at several positions on the impingement plate to account for an exact evaluation of the heat transfer coefficient. In addition to the measurements, a numerical analysis using the commercial CFD software package ANSYS CFX is conducted. Heat transfer predictions are compared with those obtained from experiments with regards to local distributions as well as averaged quantities. A good overall agreement is found but discrepancies for local values need to be accepted. The present investigation also emphasizes that configurations including rib roughness elements should be compared based on the amount of transferred heat flux in order to account for the area enlarging effect. This allows a correct evaluation of the thermal performance. [DOI: 10.1115/1.4006155]
\end{abstract}

Keywords: jet impingement, impingement cooling, impingement array, surface ribs, experimental, numerical, $C F D, T L C$

\section{Introduction}

Jet impingement systems provide an effective means for the intensification of convective processes due to the high heat and mass transfer rates that can be achieved. The range of industrial applications, which impinging jets are being used in today, is correspondingly wide. In turbomachinery, jet impingement has been routinely used over a long time for the cooling of various components, most especially turbine vanes and blades or combustion chamber walls. However, demands for increased power output, higher thermal efficiency, and reduced emissions require continuous development of the cooling technology. In particular for combustor liners, design emphasis has changed from formerly used film cooling to convective cooling concepts using arrays of impinging jets [1]. However, these systems of multiple jets are known to suffer from severe flow interactions that conflict both cooling efficiency and uniformity [2]. This is particularly true for configurations where the discharge flow is routed through only one exit (referred to as maximum cross-flow scheme) which is at the same time a very common configuration encountered in turbomachinery cooling applications. Heat transfer enhancement for such configurations therefore remains a challenging and important issue. One approach that will be followed within the present investigation is to alleviate this degrading effect of cross-flow by the introduction of surface ribs onto the target plate.

Impingement cooling configurations of different kinds have been investigated in numerous studies in the past. Several reviews have been published on the subject aimed at summarizing the latest developments in impingement technology, measurement technique,

Contributed by the Heat Transfer Division of ASME for publication in the Journal OF HeAt TRAnSFER. Manuscript received March 4, 2011; final manuscript received January 20, 2012; published online May 29, 2012. Assoc. Editor: Alfonso Ortega. and numerical computations. Among these are, for example, the works of Martin [3], Polat et al. [4], Han and Goldstein [5], Viskanta [6], or a more recent contribution by Weigand and Spring [7]. Among the variety of impingement configurations, those for the cooling in turbomachinery differ from those for other components in terms of the dimensionless quantities involved. For example, the jet Reynolds number $\operatorname{Re}$ will easily reach values $\operatorname{Re}>30,000$. Consequently, experimental investigations are costly due to the large geometries required to avoid flow Mach numbers to reach into the compressible regime $(\mathrm{Ma}<0.3)$. Such arrays, with both inline and staggered jet arrangement, were investigated in a number of studies, e.g., by Metzger et al. [8] or Florschuetz et al. [9]. They evaluated the influence of cross-flow and reported the significant decrease of heat transfer rates mentioned earlier. In Ref. [2], correlations for array jet impingement heat transfer were developed that are still being used in the thermal design process today. The effect of crossflow was addressed also by Obot and Trabold [10] in a detailed manner. The authors compared average heat transfer rates for different cross-flow schemes and confirmed that heat transfer is decreasing with increasing flow restriction, which corresponds to stronger cross-flow. These trends were confirmed by a more recent investigation from the author group of this paper, where detailed locally resolved heat transfer rates are reported [11].

The concept of acting against the effect of cross-flow induced heat transfer degradation by the introduction of surface roughness elements has been investigated in some studies. However, considering the high potential of increasing the overall amount of transferred heat flux at relatively low manufacturing costs, the available body of literature seems relatively small. A comprehensive study of several surface enlarging elements was conducted by Annerfeldt et al. [12]. By the tested triangle-shaped, wing-shaped, cylindrical, and rectangular elements, average Nusselt numbers could be enhanced by a factor of $1-1.3$. However, the authors noted that an 
additional pressure drop must be taken into consideration, which tends to reach high levels, and is strongly determined by the channel blockage due to the ribs. In conclusion, a geometry similar to a rectangular rib or a cylinder was recommended. Trabold and Obot [13] considered inline arrays of impinging jets with Reynolds numbers between 1300 and 21,000. For the maximum cross-flow scheme, they found the presence of the roughness elements to cause small reductions in heat transfer in the upstream section of the array while a significant improvement was achieved in the downstream part. They also reported the magnitude of heat transfer enhancement to depend on the open area and on the separation distance. Chang et al. [14-16] conducted parameter variations for the rib dimensions and the rib positioning at Reynolds numbers between 7000 and 20,000. They found that the relative position of the jet hole to the ribs has a significant effect on heat transfer. The most effective arrangement was obtained by placing the jet holes in-between a pair of ribs. An empirical correlation was derived from the extensive amount of different flow conditions and geometric parameters. Andrews et al. [17] investigated the effect of rib orientation relative to the spent air cross-flow. For longitudinal ribs, better heat transfer is achieved for co-flow conditions, while for slotted ribs, the reverse applies. For such slotted ribs, Andrews et al. [18] stated that for the best enhancement of heat transfer in the presence of cross-flow, the roughness element blockage should be large (50\%). Nam et al. [19] showed locally resolved heat transfer coefficients and compared rectangular ribs at different densities and angles of incidence relative to the spent air flow. The $90 \mathrm{deg}$ ribs were found to increase heat transfer the most. It was concluded that the choice of rib configuration allows altering the local heat transfer distribution significantly, e.g., by shifting the point of maximum heat transfer, and thus allows for a tailoring of local cooling needs. Detailed heat transfer measurements in the form of local distributions were also presented by Son et al. [20,21] for different element types. The results showed that the elements enhance total heat transfer performance of the impingement cooling system at low pressure penalty. The effect of fillet radii was evaluated but only little difference was reported between rounded and sharp-edged elements. Yan et al. [22] and Yan and Mei [23] also presented locally resolved heat transfer contours for rectangular ribs at 45, 60, and $90 \mathrm{deg}$ ribs. For their configuration, $45 \mathrm{deg}$ ribs were found to increase average Nusselt numbers and continuous ribs gave better results than broken ribs.

Over recent years, numerical simulation tools, namely, computational fluid dynamics (CFD) codes, have matured to efficient tools for the thermal design of different engineering applications. For the numerical modeling of jet impingement heat transfer, several studies exist that have investigated fundamental questions for these types of flow, e.g., on the choice of turbulence model. These are, for example, the studies of Zuckerman and Lior [24] or Coussirat et al. [25]. The recent progress in applied CFD for different kinds of jet impingement configurations has also been reviewed in Ref. [26]. As shown therein, a high accuracy can be achieved in the prediction of jet impingement heat transfer even for complex systems with multiple jets. Such results can be obtained by industry-standard CFD software and at reasonable computation times. For impingement configurations with surface ribs, however, barely any numerical studies exist in literature. Although Jia et al. [27] conducted a numerical study of impingement cooling in ribbed ducts, the authors missed to evaluate their results by comparison with experimental data which is an inevitable element for an assessment of the predictive accuracy.

The present study investigates the heat transfer from arrays of multiple impinging circular air jets combined with surface ribs. The objectives are to investigate the heat transfer and pressure loss from the impingement on a flat and roughened plate. Through the literature survey, one can see that the influence of the ribs is closely related to the cross-flow. In the current study, two array models with different rib configurations are considered: An inline jet arrangement with continuous ribs aligned perpendicular to the direction of cross-flow and a staggered jet arrangement with broken ribs aligned with the direction of cross-flow. The jet Reynolds number is 35,000 , the distance between nozzle and target plate is $H / D=3$, and the jet-to-jet distance is $S_{x}=S_{y}=5 D$. These parameters correspond to conditions that may well occur in turbomachinery. The ribs have a height of $e / D=1$ which corresponds to a channel blockage ratio of 0.33 . Only the maximum cross-flow condition is considered, as it has been reported consistently that the potential to increase heat transfer by roughness elements is highest for conditions with strong cross-flow $[12,13,17,18]$. This can also be seen from the results shown in the study of Xing and Weigand [28], where preliminary tests and additional results for this setup are reported. The experimental study is complemented by a comprehensive numerical part. The computational model is constructed to precisely represent conditions in the experiments while at the same time keeping the computational costs as low as possible. The quality of the heat transfer predictions is evaluated by comparison with experimental data for local distributions and average values. This serves, on the one hand, to determine the degree of accuracy for the results as obtained by a commercial CFD software. The latter is important to evaluate whether CFD can be used as a tool in the design and optimization of such complex geometries. On the other hand, the CFD computations allow the consideration of effects such as rib surface heat transfer that are not easily measurable. As the present investigation will show, these effects are quite important when assessing the overall thermal performance. The motivation and objectives of the present paper can thus be summarized as follows: (1) conduct experiments on full-scale impingement arrays with rib-roughened surfaces, (2) evaluate the accuracy of CFD heat transfer predictions for the problems considered, and (3) evaluate the thermal performance of the configurations by additional data provided by the CFD analysis.

Details on the experimental setup, the investigated configurations, the measurement technique, and uncertainties are provided in Sec. 2. The numerical setup is introduced in Sec. 3. A brief description on the flow solver, the computational domains, and the numerical grids are given. For an assessment of numerical accuracy, the outcome of a systematic mesh sensitivity analysis is discussed. Section 4 first shows the results obtained from both measurements and CFD predictions with comparisons of each other. Finally, the tested configurations are compared. The main conclusions of this investigation are summarized in Sec. 5.

\section{Experimental Setup}

2.1 Test Rig. Figure 1 shows a sketch of the test rig. A vacuum pump system was used to generate the desired air flow in the test section. The air entered under atmospheric conditions via a filter and a mesh heater, which was able to heat the air within less than $0.3 \mathrm{~s}$ from ambient temperature up to approximately $100^{\circ} \mathrm{C}$. Downstream of the heater, the air was routed through an inlet plenum and entered into the actual impingement model. This model consisted of an impingement plate with the respective hole arrangement (inline or staggered), the target plate, and the side rims, of which one was equipped with effusion holes to allow the

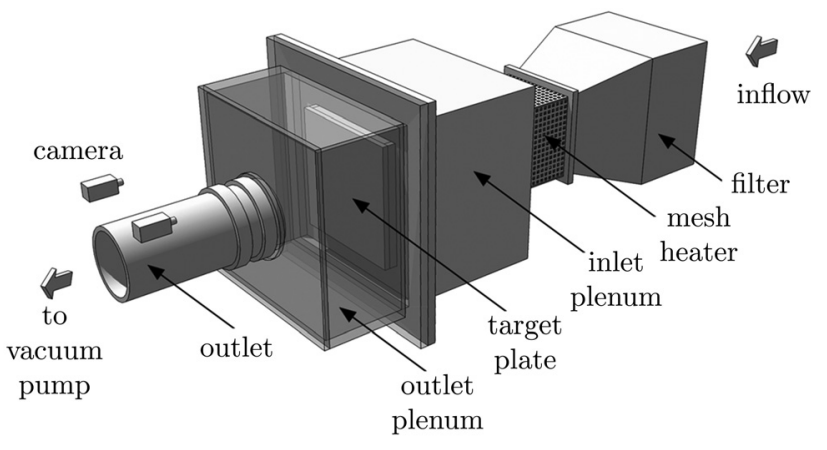

Fig. 1 Three-dimensional schematic of the test rig 


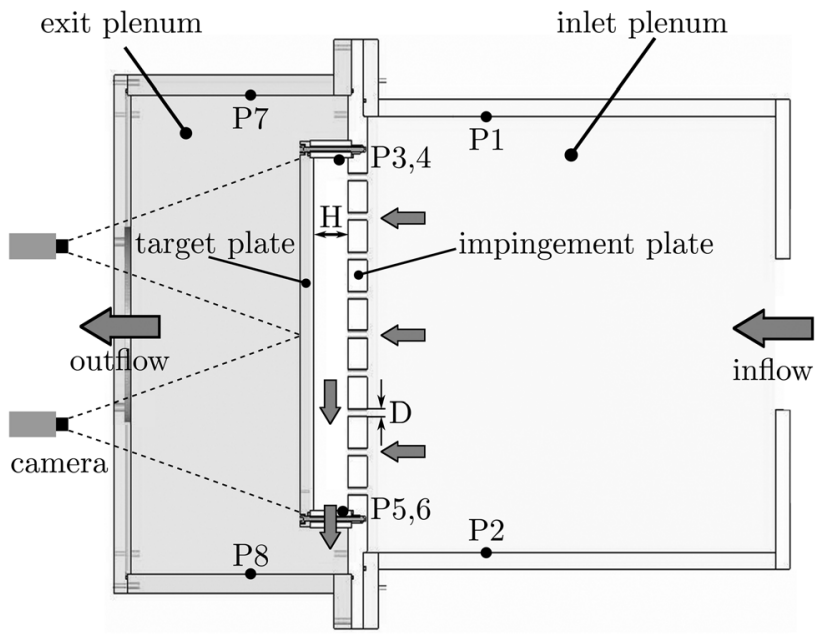

Fig. 2 Cross-sectional view through the impingement rig

flow to exit into the outlet plenum. The presence of only one outlet resulted in a strong secondary flow due to spent air within the array (maximum cross-flow condition). The test rig was equipped with several pressure taps at different locations as indicated in the cross-sectional view in Fig. 2. The target plate was made of perspex because of its low thermal conductivity and the optical access that was needed for the heat transfer measurements. The target plate was observed from the outside by two CCD video cameras. The model was symmetrical; therefore, only half of the target plate was observed.

For both investigated configurations, the ratios of jet-to-jet spacing in streamwise and spanwise direction were identical, i.e., $S_{x} / D=S_{y} / D=5$. The jet Reynolds number, which is based on the jet diameter, was 35,000. This value represents an average over the whole array. The distance between the impingement plate and the target plate was $H / D=3$. A large number of thermocouples was installed and placed directly into the jet exits (blocking approximately $1 \%$ of the total jet area). They were held firmly in position by grooves milled into the impingement plate (see Ref. [29] for schematic and details). These thermocouples served to measure the jet total temperature which was then used for the evaluation of the heat transfer coefficient. The large number of thermocouples allowed accounting for temperature variations across the jets. By means of a specific software developed at Institute of Aerospace Thermodynamics, these signals recorded at the different positions were then interpolated both spatially and temporally and thus allowed a determination of the correct bulk temperature for the heat transfer coefficient [30].

2.1.1 Configuration I. In the inline arrangement, there were a total of 81 impingement holes. Figure 3 shows a schematic includ-

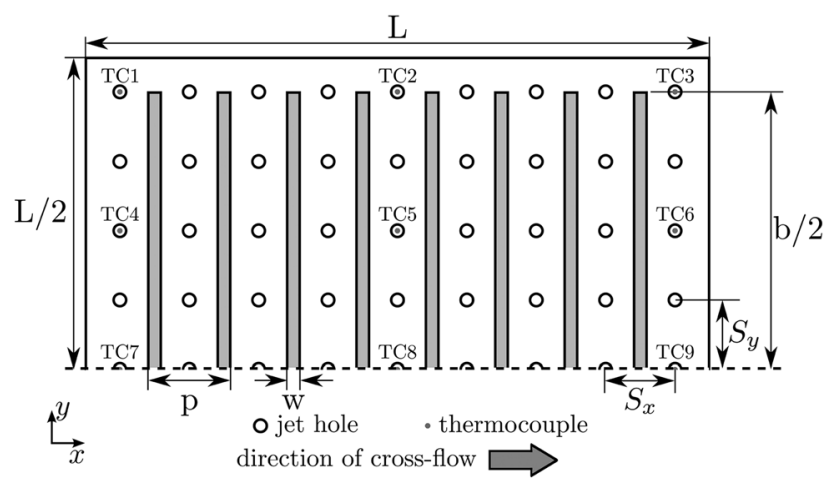

Fig. 3 Schematic of configurations I

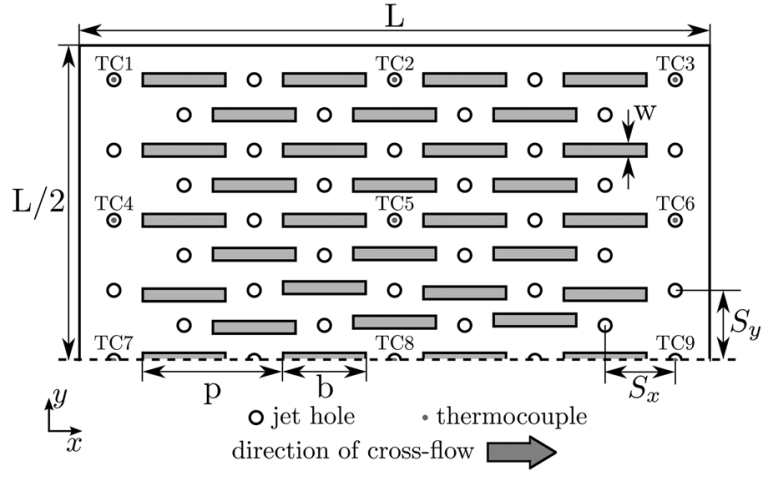

Fig. 4 Schematic of configurations II

ing the positions of the installed thermocouples. Note that due to the symmetry only half of the model is shown. The positions of the rib elements can also be seen from the figure. For both configurations, rib width and height were identical to the jet diameter, thus $w / D=e / D=1$. In configuration I, the distance in streamwise direction (along the $x$-axis) measured $p / D=5$ and the overall rib dimension in $y$ direction was $b / D=40$.

2.1.2 Configuration II. For the staggered case, 77 jets were distributed across the impingement plate in a regular pattern. Figure 4 shows a schematic. In this configuration, the ribs were located in-between streamwise pairs of jets. Here, streamwise distance measured $p / D=10$ and the rib length in streamwise direction was $b / D=6$.

2.2 Measurement Technique. A transient method using thermochromic liquid crystals (TLC) was applied for the determination of heat transfer [31]. Narrow bandwidth liquid crystals (with an indication temperature of $31^{\circ} \mathrm{C}$ ) were used. The TLC indication temperature was determined in preliminary tests by means of a calibration unit (simulating 1D axial heat conduction) consisting of a block of copper, electric heater, and accommodate water cooling. The liquid crystals were sprayed directly onto the target plate and then covered with a coating of black paint to provide a uniform background for the image acquisition. Note that the rib elements were not included in the heat transfer measurement.

Local heat transfer coefficients were determined from the measured wall temperature and the solution of the one-dimensional transient heat conduction equation for a semi-infinite solid. This assumption can be considered valid as long as the condition $\alpha t / D^{2}<1 / 4$ is fulfilled [32]. Here, $\alpha$ is the thermal diffusivity of the material. With typical material properties of perspex and the present wall thickness of $20 \mathrm{~mm}$, the assumption of the semiinfinite wall was fulfilled as long as the maximum testing time did not exceed $90 \mathrm{~s}$.

For a flat surface, the wall surface temperature and the heat transfer coefficient are related by the expression

$$
\Theta=\frac{T_{w}-T_{0}}{T_{B}-T_{0}}=1-\exp \left(\tilde{x}^{2}\right) \operatorname{erfc}(\tilde{x})
$$

where

$$
\tilde{x}=h \sqrt{\frac{t}{k \rho c}}
$$

In the present study, Eq. (1) was solved numerically and the heat transfer coefficient could thus be obtained from the measured wall temperature $T_{w}$ at time $t$ by which this temperature was reached (indicated by the color change of the liquid crystals). In theory, Eq. (1) is only valid for an ideal temperature step within the flow, but in reality, the thermocouple records a time-dependent 
temperature evolution. To overcome this problem, the temperature data were divided into a series of small discrete intervals $N$. For these intervals, the temperature evolution could be considered as ideal temperature step. Thus, Eq. (1) was extended according to the Duhamel principle [33]

$$
T_{w}-T_{0}=\sum_{i=1}^{N} \Theta\left(t-t_{i}\right)\left(T_{B, i}-T_{B, i-1}\right)
$$

where $T_{B, i}$ is the bulk temperature at one specific time $t_{i}$.

Pressure drop for the system was measured by static pressure taps along the walls of the test section. Their axial positions $\left(P_{1}-P_{8}\right)$ are sketched in Fig. 2. The discharge coefficient $C_{D}$ is a common measure for the pressure loss of flow systems. In the present work, discharge coefficients for the exit rims were defined for an incompressible flow as

$$
C_{D}=\frac{\dot{m}}{\rho A} \sqrt{\frac{\rho}{2 \Delta P_{0}}}
$$

with

$$
\Delta P_{0}=\frac{1}{4}\left(P_{3}+P_{4}+P_{5}+P_{6}\right)-\frac{1}{2}\left(P_{7}+P_{8}\right)
$$

2.3 Measurement Uncertainties. Accuracy of the measured heat transfer coefficients is biased mainly by the accuracy of the thermocouples, the calibration of the liquid crystals, and the accuracy of the time detection. The approach used herein to quantify the measurement uncertainties is based on the method of Ref. [34].

Accuracy of the Reynolds number was determined by measurement of the volume flow using a vortex meter and by the range of the static pressure sensors. The resulting uncertainty for the jet Reynolds number was calculated to be below $2.5 \%$. For the narrow band TLC, the transitional temperature range was $1{ }^{\circ} \mathrm{C}$ with a typical uncertainty in measuring this temperature of approximately $0.1^{\circ} \mathrm{C}$ [35]. $T_{B}$ and $T_{0}$ were measured with thermocouples, for which a thermocouple calibration procedure guaranteed that the error was below $0.2^{\circ} \mathrm{C}$.

These measurement uncertainties vary with adiabatic wall temperature and therefore depend on the local position on the target plate. In particular in the stagnation zones of the jets, one can assume lateral heat conduction to influence the results considerably. Kingsley-Rowe et al. [36] used an approximate twodimensional analysis to calculate the error. Here, we used a 2D finite-difference solution of Fourier's equation to validate the method. Accordingly, the maximum error for the heat transfer coefficient due to lateral heat conduction has been calculated to be below $2 \%$ when the dimensionless temperature ratio $\Theta$ is in the range of $0.3 \leq \Theta \leq 0.7$. In total, the measurement uncertainty for the heat transfer coefficient was estimated to be below $9 \%$ for all tests carried out within this study. The maximum error for the pressure measurements, which mainly depended on the range of the pressure sensors, was estimated below $2.5 \%$.

\section{Computational Details}

3.1 Flow Solver. For the numerical investigation of the impingement configurations, the commercial CFD software package ANSYS CFX version 11 was used. Spatial discretization was based on the second-order accurate central difference scheme with an automatic blending into a first-order upwind scheme in case of oscillations. All computations were of steady-state.

Due to its good performance in predicting the heat transfer in jet impingement configurations at relatively low computational costs, the SST turbulence model was used in all computations [26]. The model description is available in Ref. [37]. This model uses a low-Reynolds number approach for describing the flow near a wall, which thus allows accounting for details in the viscous sublayer. The method requires very fine mesh length scales near the wall in the sense that the dimensionless wall distance of the first node in the flow is $y_{1}^{+}<2$. Here $y_{1}^{+}$is defined as

$$
y_{1}^{+}=\frac{U_{\tau} y_{1}}{\nu}
$$

where $U_{\tau}$ is the shear velocity, $\nu$ is the kinematic viscosity of the fluid, and $y_{1}$ represents the absolute distance of the first grid cell to the wall.

3.2 Domain and Boundary Conditions. The computational domain was generated following the geometric specifications of the experimental facility as accurately as possible in order to assure a realistic representation of the measurements. Some simplifications were introduced that helped to increase mesh resolution on the available computing resources. Outlet holes from the exit rims and the outlet plenum were not included in the model as both were assumed to influence upstream flow conditions only to a minor extent. Symmetry boundary conditions were applied where possible in order to reduce the overall size of the computational model further. For the considered maximum cross-flow case, this allowed to reduce the original $9 \times 9$ array to one line of jets $(9 \times 1)$. This is shown in Fig. 5 .

Boundary conditions were defined in accordance with the data collected during the experiments. Measured massflow rates were applied as inlet conditions to the inflow plenum. In the numerical investigation, the incoming flow had a uniform temperature approximately $30 \mathrm{~K}$ lower than the heated target plate. The turbulence intensity for the incoming flow defined as

$$
I_{0} \equiv \frac{\bar{u}}{\bar{U}}
$$

was $I_{0}=0.1$. Here, $\bar{u}$ is the root-mean-square of $1 / 3$ of the turbulent normal stresses

$$
\bar{u} \equiv \sqrt{\frac{1}{3} \overline{u_{i} u_{i}}}
$$

and $\bar{U}$ is the mean jet velocity computed as

$$
\bar{U} \equiv \sqrt{\left(U^{2}+V^{2}+W^{2}\right)}
$$

From this, the boundary conditions for turbulence kinetic energy $k_{0}$ and dissipation rate $\varepsilon_{0}$ at the inlet were obtained from

$$
k_{0}=\frac{3}{2}(I \bar{U})^{2}
$$

and

$$
\varepsilon_{0}=\rho C_{\mu} \frac{k_{0}^{2}}{\nu_{t}}
$$

respectively. For the eddy-viscosity, it was $\nu_{t, 0}=100 \nu$ at the inlet. The target plate was considered as no-slip wall with a constant temperature boundary condition, whereas the impingement plate and the plenum walls were modeled as adiabatic no-slip walls. Thus, the thermal boundary conditions differed from those of the experiments. However, the effects of temperature ratio and fluid properties can be considered negligible as long as the temperature differences between the wall and the fluid are small, which is the case here. However, one should keep in mind that these conditions do not hold for real turbomachinery applications. At the outlet, a constant pressure entrainment boundary condition was prescribed using a zero-gradient condition for the outgoing flow and constant 


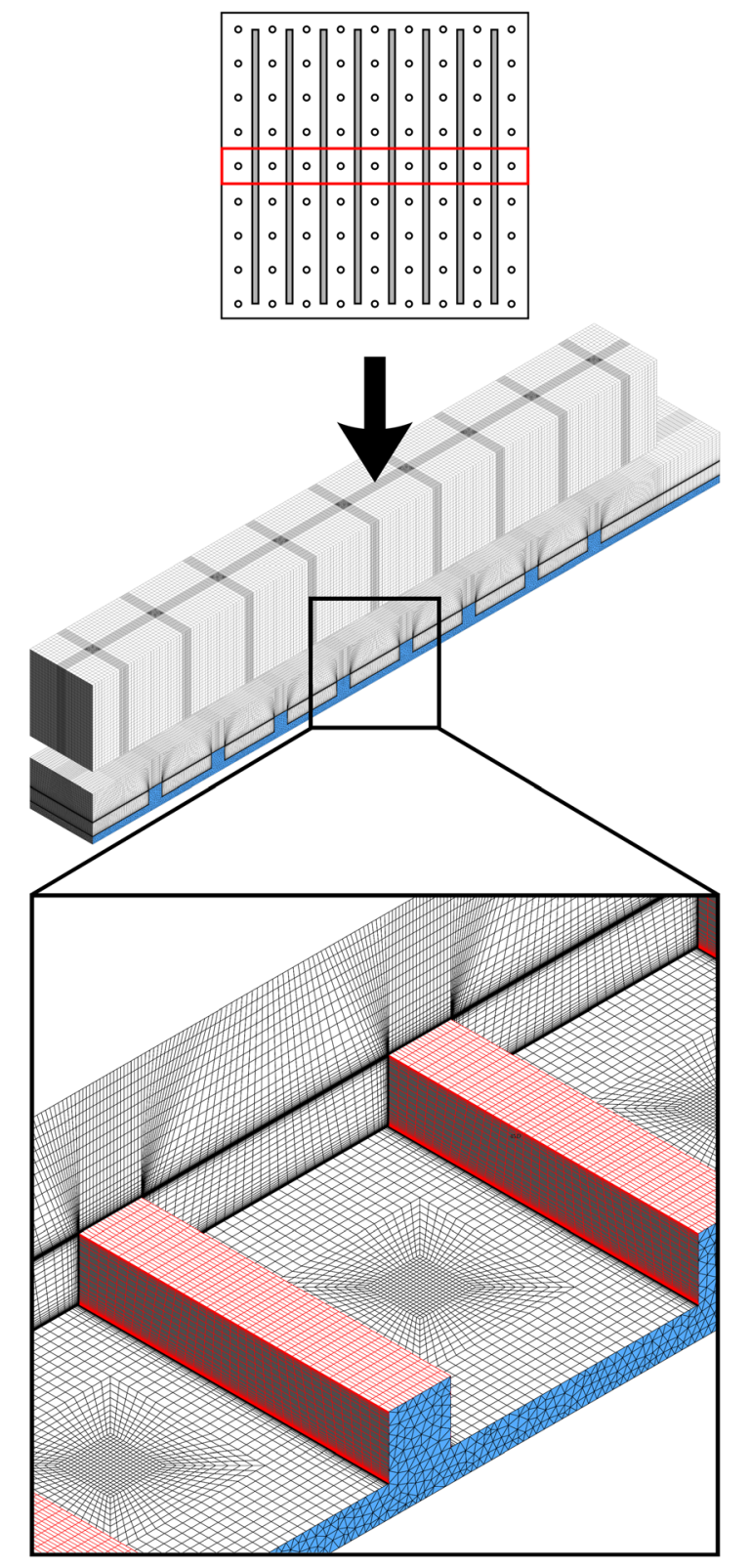

Fig. 5 Schematic of computational domain and view on the mesh representing configuration I

variable values for the incoming flow. The two sides parallel to the mainstream direction were symmetry planes.

3.3 Computational Grid. Meshes for the CFD analysis were generated with ANSYS ICEMCFD version 11. Spatial discretization of the domain was realized by block-structured grids with hexahedral elements. A three-dimensional view on the grid for configuration I is shown in Fig. 5 as an example. The corresponding volume in the original experimental setup is indicated as well. The domain size of configuration II is identical.

Very fine mesh scales in the direction normal to the wall were applied to the target plate as well as to all surfaces of the roughness elements. This ensured the proper functionality of the lowReynolds number turbulence model, which requires the dimensionless wall distance of the first grid point to be smaller than 2 , on all walls where heat transfer was considered. Small cell growth rates (not greater than 1.2) were used for all surfaces normal to the direction of impingement. For all element surfaces, cell growth rates were allowed to be higher but not greater than 1.5. O-grids were
Table 1 Grid parameters for configurations I and II

\begin{tabular}{lcc}
\hline \hline & Configuration I & Configuration II \\
\hline$N$ & $2,365,136$ & $9,531,144$ \\
$\Delta y / D$ & $4 \times 10^{-4}$ & $4 \times 10^{-4}$ \\
$y_{1}^{+}$ & 0.64 & 0.58 \\
$y_{i+1} / y_{i}$ & 1.2 & 1.2 \\
\hline \hline
\end{tabular}

applied to the inside and the outside of the jets in order to obtain high cell orthogonality. Grid cell numbers $(N)$ along with details on the near-wall resolution for investigated cases are listed in Table 1. The cell expansion rate $y_{i+1} / y_{i}$ describes the rate of change in the magnitude of adjacent elements. Note that values for $\overline{y_{1}^{+}}$represent an average of the dimensionless distance between the wall and the first cell outside the wall. The averaging was done over all surfaces where heat transfer is considered, i.e., on the target plate and on all element surfaces.

3.4 Quantification of Numerical Accuracy. For an estimate on the discretization error, we selected a method that is well established in CFD studies and supported by the Fluids Engineering Division of ASME [38]. The method is based, in principle, on the generalized Richardson extrapolation theory but has been developed into a more generalized formulation applicable to a wider range of practical cases by Roache [39]. The resulting grid convergence index (GCI) method can be regarded as a procedure for the uniform reporting of grid refinement studies. The method yields discretization error bands for the investigated variable and thus represents an objective measure of mesh dependency. However, it is important to note that the GCI method, by definition, cannot account for general modeling errors, such as the choice of boundary conditions or turbulence model; only the error due to an insufficient spatial resolution can be quantified. Within the present investigation, the GCI method complied with all of its following requirements: The grid refinement was done systematically, which means that all grids were refined uniformly in every direction of space. Distances between the walls and the respective first nodes off the surface were also scaled to account for changes in $y_{1}^{+}$. The mesh sensitivity analysis was carried out for configuration I only as the results were considered representative of the other configuration. The focus was set on an accurate quantification of the uncertainty as prerequisite for a meaningful conclusion on mesh sensitivity and for an interpretation of results. Therefore, mesh dependency was analyzed for local distributions rather than average values. Relevant parameters of the different meshes are summarized in Table 2. Here, $N$ is the total number of cells and $\overline{y_{1}^{+}}$is the total average of the dimensionless wall distance of all heat transfer surfaces. The resulting distribution of the total GCI calculated by means of the three different grids is shown in Fig. 6 in the form of centerline Nusselt numbers. Note that heat transfer rates on the rib surfaces are omitted for better clarity. To the experimental data, a constant uncertainty of approximately $9 \%$ was added graphically for visualization purposes.

In summary, estimated discretization errors were relatively low confirming that the mesh resolution was appropriate for the problem considered. Increased errors occurred around some stagnation zones, which explain by the steep gradients in this area reacting very sensitive to changes in mesh resolution. The discretization error with regards to an area averaged Nusselt number (averaged

Table 2 Grid parameters of the refinement study

\begin{tabular}{lrc}
\hline \hline Grid & $N$ & $\overline{y_{1}^{+}}$ \\
\hline Fine & $2,365,136$ & 0.64 \\
Intermediate & $1,086,663$ & 0.80 \\
Coarse & 461,940 & 0.99 \\
\hline \hline
\end{tabular}




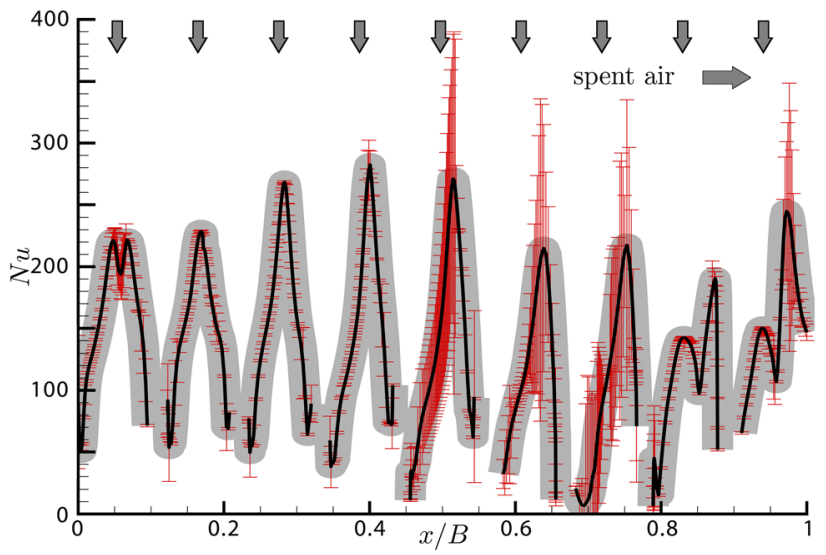

Fig. 6 Calculated GCI error band for centerline Nusselt numbers on the fine grid of configuration I

over the entire target plate including the roughness elements) was $3 \%$. Absolute local values are estimated to be within an uncertainty of less than $10 \%$. Most of the estimated errors are within the measurement uncertainty.

\section{Results and Discussion}

4.1 Configuration I. Figure 7 shows a comparison of experimental and numerical results in the form of local Nusselt number distributions. The upper plot represents experimental data while the lower plot is CFD data. Heat transfer on the element surfaces was not taken into account as these were not considered in the experiments.

From a visual comparison of the Nusselt number distributions, the numerical results reproduced the main characteristics of the experiments. This applied, for example, to the shapes of the jet footprints on the target plate, the locations of the stagnation zones, and the effects of cross-flow on the heat transfer contours. Upstream Nusselt numbers were higher in the CFD results than in the experimental distributions. This was probably related to a combination of inhomogeneous mass flow distribution and a quite large temperature gradient for the incoming flow that were observed in the test rig. Next to the outlet, large differences between experiments and CFD occurred. In the experiments, the last jet obviously did not reach the target plate. This could mean that the cross-flow was very strong deflecting the jet outside of the observed area. It is also possible that the flow was unsteady so that the last jet was performing a periodic movement in spanwise direction. The result of this would be that there exists no distinct point of maximum heat transfer but only zone of medium heat transfer (a smoothed and smeared peak). However, the TLC method is not suited for tracking

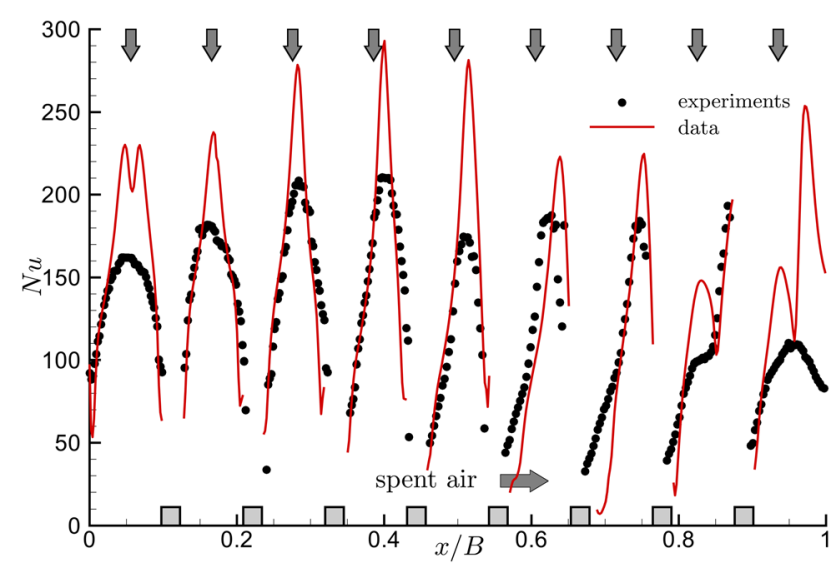

Fig. 8 Comparison of centerline Nusselt number distributions for configuration I

back the flow pattern from the observed temperature change at the wall. For further analysis, one would need to conduct additional studies on the flow field, e.g., particle image velocimetry (PIV) measurements. It should also be noted from Fig. 7 that the numerical results showed some asymmetry, which could be an indicator for the unsteadiness of the flow even though the computations were of steady-state. A qualitative comparison in the form of centerline Nusselt number distributions is presented next in Fig. 8.

Here, relatively large differences occurred in most of the stagnation points where the heat transfer rates predicted by the CFD computations were significantly higher than the experimental values. This is a problem that is typical for the numerical prediction of jet impingement heat transfer by eddy-viscosity models. Its reason lies in the production rate of turbulence kinetic energy, for which these models tend to generate excessive levels in presence of large streamwise velocity gradients [40]. The deflections of the jets by the cross-flow were captured quite well which is interesting to note as such streamline curvature is also a common problem for eddy-viscosity type turbulence models [41]. Close to the outlet, numerically predicted Nusselt numbers departed significantly from the experimental data as could already be seen in the comparison of contour plots in Fig. 8. Spanwise-averaged heat transfer coefficients are compared next in Fig. 9. These are important as they are a measure for the lateral variation in heat transfer.

Here, one can see a similar trend as in the previous figures. The shapes of the Nusselt number distributions agree well, whereas the areas of the stagnation zones are again overpredicted. As now the lateral spread is taken into account, this indicates that the jets in the numerical results produce a larger spread, or higher heat transfer rates, or a combination of both compared to the jets in the experiments. The jet spreading is interesting from a numerical point of view as it is well known to be very difficult to predict

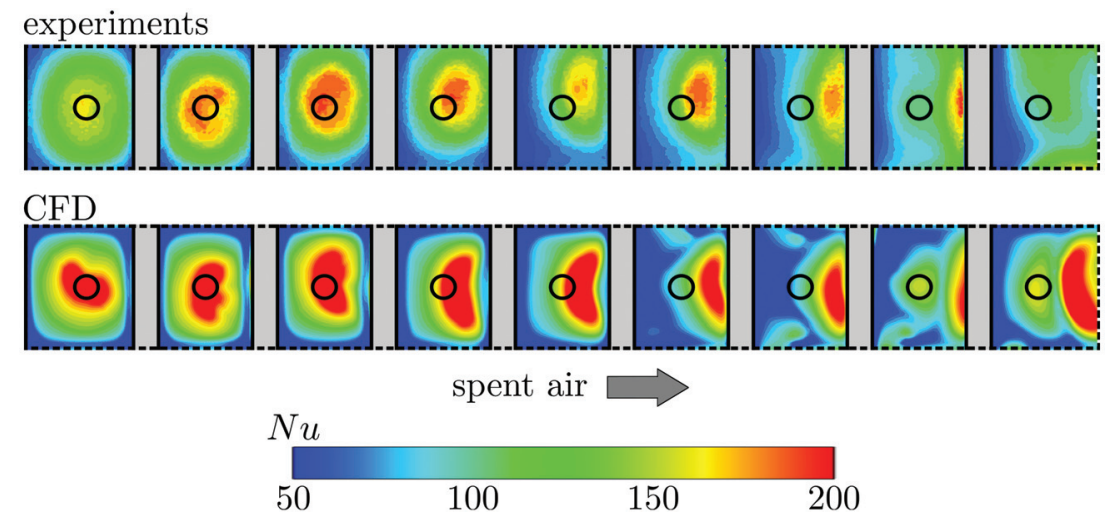

Fig. 7 Comparison of Nusselt number contours for configuration I 




Fig. 9 Comparison of spanwise-averaged Nusselt number distributions for configuration I

Table 3 Comparison of total average Nusselt numbers between experiments and CFD

\begin{tabular}{lccc}
\hline \hline & $\overline{N u}_{\text {exp }}$ & $\overline{N u}_{\text {CFD }}$ & $1-\frac{\overline{N u}_{\text {CFD }}}{\overline{N u}_{\text {exp }}}(\%)$ \\
\hline Configuration I & 96.7 & 105.1 & 8.7 \\
Configuration II & 96.3 & 92.0 & 4.4 \\
\hline \hline
\end{tabular}

with two-equation type turbulence models [42]. A quite good agreement is found in the downstream section of the array where in particular the deflection of the jets is captured quite well. However, it must also be noted that in the experimental data, spanwise-averaged Nusselt numbers were almost as high as those on the centerline. This seems somewhat unlikely and would require further experimental data for a final clarification.

Area averaged Nusselt numbers (averaged over the target plate not including the rib elements) are compared in Table 3. A reasonable agreement of less than $9 \%$ is found for this configuration.

The results for configuration II are discussed in the following.

4.2 Configuration II. In the second geometry of this investigation, the jets were arranged in a staggered pattern. Figure 10 shows contour plots of the local Nusselt number distribution. What is most evident in comparison to the results of configuration I is that the cross-flow was significantly stronger, in particular close to the outlet. This clearly illustrates why inline arrays are reported to perform better in terms of average heat transfer rates, which are typically around $15-20 \%$ higher $[9,11]$. This can be explained by the fact that in an inline arrangement, the jets of a given streamwise row tend to be shielded from the oncoming cross-flow, which is the primary cause of heat transfer degradation, by the jets of the immediate upstream row. Additionally, the flow is channelized between pairs of spanwise jet rows. For the staggered configuration, the direct influence of the cross-flow on each jet is larger, causing stronger deflection and diffusion, which finally leads to a reduced contribution to heat transfer.

In the CFD simulations, these effects of cross-flow seemed much more pronounced than in the experimental results, which is in particular visible close to the outlet. The major contributor was probably a too large jet spreading in spanwise direction that virtually magnified the effect of cross-flow by leaving smaller flow passages for it. In the upstream section of the array where only low crossflow speeds occurred, a relatively good agreement of the Nusselt number distributions was found. Similar weaknesses as for configuration I can be identified, i.e., too large maxima and too large jet spreading. These observations will be quantified further by the comparison of centerline Nusselt number distributions. Figure 11 shows the results.

The overall agreement along the centerline was fair with again significant overprediction of the stagnation point heat transfer. For the last streamwise jet, the heat transfer pattern was different from the experiments obviously because the last jet was predicted to impinge onto the target plate further downstream than in the experiments. This can be seen as a result of the too strong crossflow in the CFD results combined with the inaccuracy involved in the representation of streamline curvature effects. Off-centerline results are considered in Fig. 12 where spanwise-averaged Nusselt number distributions are compared.

Overall agreement in the upstream half was fair whereas the heat transfer in the areas in-between streamwise pairs of jets was significantly underpredicted. It is well possible that this was an effect of the missing unsteadiness in the simulations which was suppressed by the assumption of steady-state flow. The unsteady motion of the jets in the experiments helped to smoothen the heat transfer distribution and to reduce the local gradients in Nusselt number. The underprediction might also be caused, to some degree, by the assumption of isotropic turbulence that is made within the shear stress transport (SST) turbulence model. The resulting inability to account for anisotropy prohibits the generation of turbulence-driven secondary flow motions which, in the present case, might have contributed to enhance heat transfer in these areas. For such secondary flows, indications exist in literature, e.g., in Refs. [43,44], but their characteristics in arrays of impinging jets are not fully understood. In the downstream half, some very large discrepancies occurred. Here, the jets were, on the one hand, impinging mostly onto the roughness elements and thus generating only small stagnation points on the target plate (as expressed by the distinct peaks). On the other hand, cross-flow effects were much more pronounced for this configuration. However, also for this configuration, experimentally determined spanwise-averaged Nusselt numbers were relatively high compared to the centerline values and thus leave open questions that could not be answered from the available data.

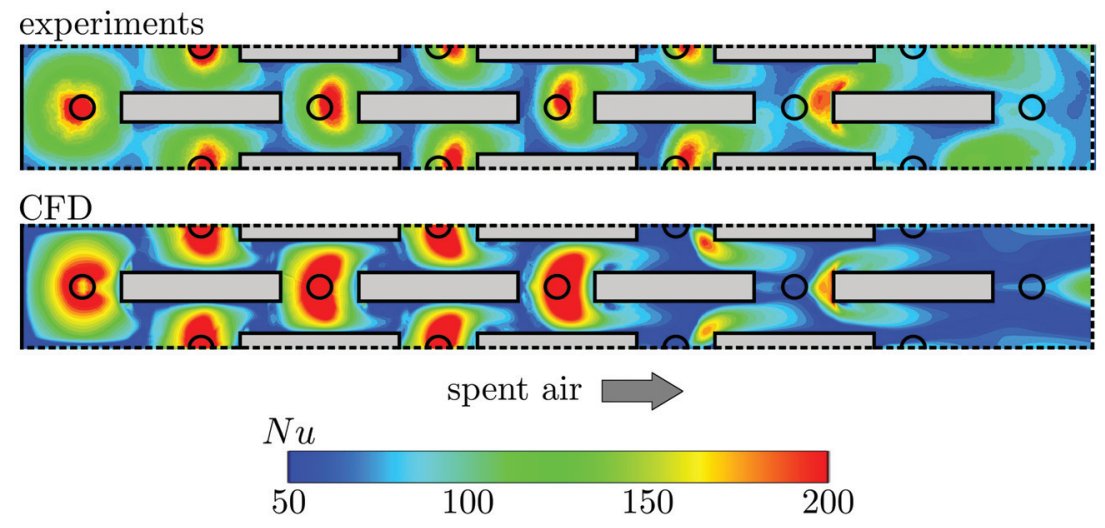

Fig. 10 Comparison of Nusselt number contours for configuration II 


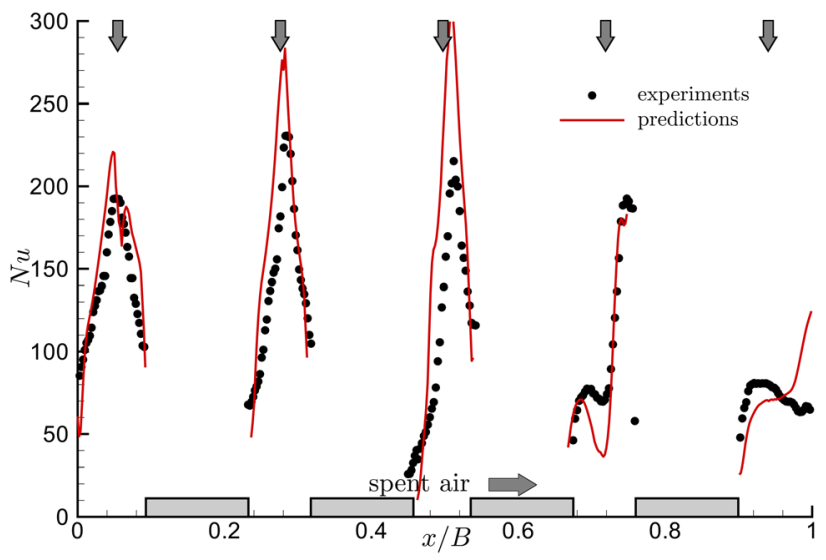

Fig. 11 Comparison of centerline Nusselt number distributions for configuration II

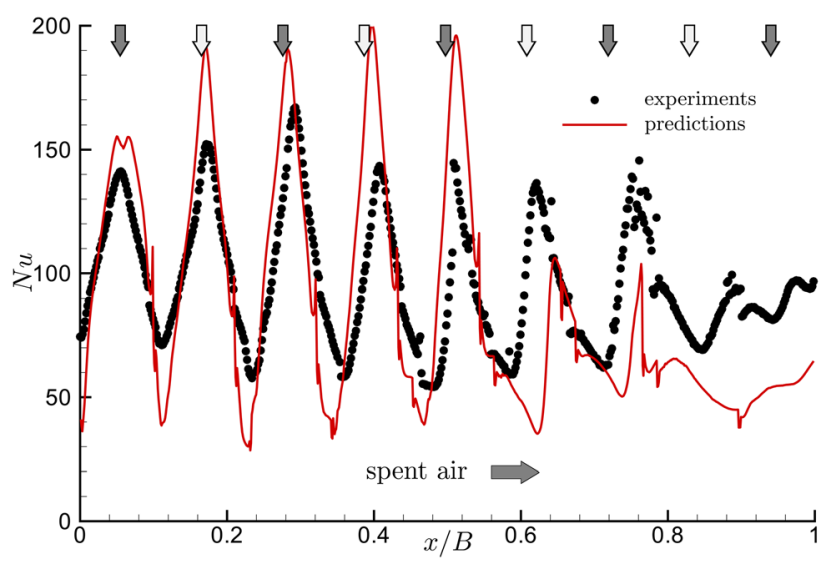

Fig. 12 Comparison of spanwise-averaged Nusselt number distributions for configuration II

Area averaged Nusselt numbers for the target plate, not including the roughness elements, are compared in Table 3. Here, the present configuration showed a good agreement. It can therefore be concluded that the numerical predictions may be used at sufficient confidence for an assessment of the overall heat transfer (in form of average quantities). When local heat transfer rates are to be evaluated numerically, a comparison with experimental data seems inevitable unless very large uncertainties can be accepted.

4.3 Summary of Findings. In this section, the two tested configurations are compared. In order to consider the full effect of the roughness elements, heat transfer data are taken from the CFD simulations which allow accounting for heat transfer on the element surfaces. The CFD data should suffice to describe the trends in heat transfer performance for the different configurations. The configurations are compared by means of area averaged Nusselt numbers resolved to one streamwise hole spacing (corresponding to an area of $5 D \times 5 D$ ). The results are shown in Fig. 13. Note that the Nusselt numbers were referred to the corresponding values of the unribbed target plate (denoted by index 0 ). These values were taken from CFD data of the previous investigation [11]. Note that the surfaces of the roughness elements are now included in the analysis.

The roughness elements did not show any improvement in Nusselt number for configuration I when compared to the unribbed target plate. While the very upstream region was relatively unaffected, heat transfer coefficients in the midsection were even lower than those from the flat plate configuration. This was due to the major fraction of the jet flow impinging directly onto the rib

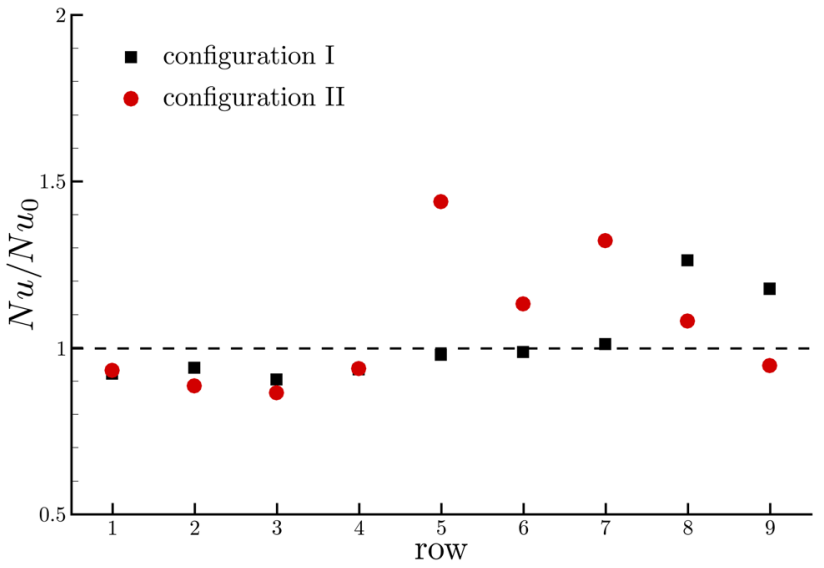

Fig. 13 Row-wise averaged Nusselt number ratios for configurations I and II



Fig. 14 Row-wise averaged ratios of amount of transferred heat flux for configurations I and II

elements. This prohibited the impingement onto the target plate and thus resulted in the low heat transfer rates in the areas between pairs of streamwise ribs. Heat transfer degradation was increased further by the fact that the downstream jets were subject to locally stronger cross-flow effects due to the reduced channel cross-sectional area caused by the roughness elements.

For the staggered jet pattern, the ribs partially helped to alleviate the strong degrading effects of cross-flow typically found in the downstream half of an unribbed impingement array. For this particular configuration, the enhancement could have been caused by the ribs separating the cross-flow from the impingement zones. By this, good results were obtained for the midsection of the field. At the same time, the ribs were slightly restricting the lateral spread of the jets, which was visible in the upstream part and had detrimental effects on heat transfer. In the very downstream part, only a moderate improvement was achieved. Here, it seemed again as if the jets were impinging more onto the rib elements than on the target plate. This can be explained by the large crossflow speeds that must have occurred in this configuration due to the high channel blockage.

For a rating of the thermal performance, the amount of transferred heat flux is considered next. This parameter, in contrast to the Nusselt number, accounts for the important effect of area enlargement due to the roughness elements and therefore is of specific importance. Results are shown in Fig. 14 in the form of row-wise averaged values $(5 D \times 5 D$ segment). Note that the amount of heat flux, $\dot{Q}$, has again been referenced to the value of the respective unribbed target plate $\dot{Q}_{0}$. Both datasets were again 


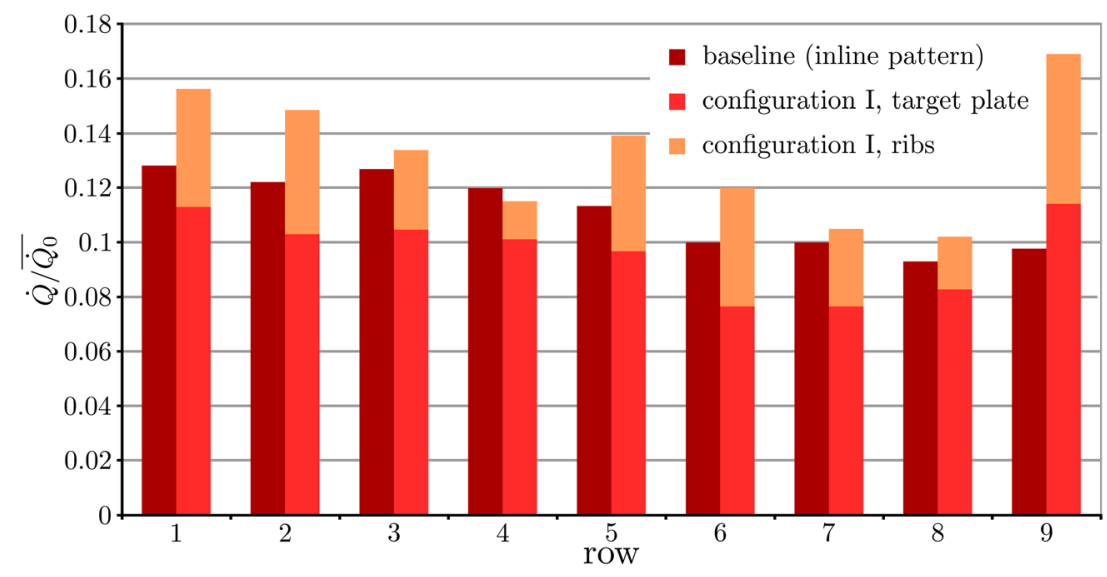

Fig. 15 Contribution of the individual surfaces to the total amount of transferred heat flux for configuration I and unribbed counterpart

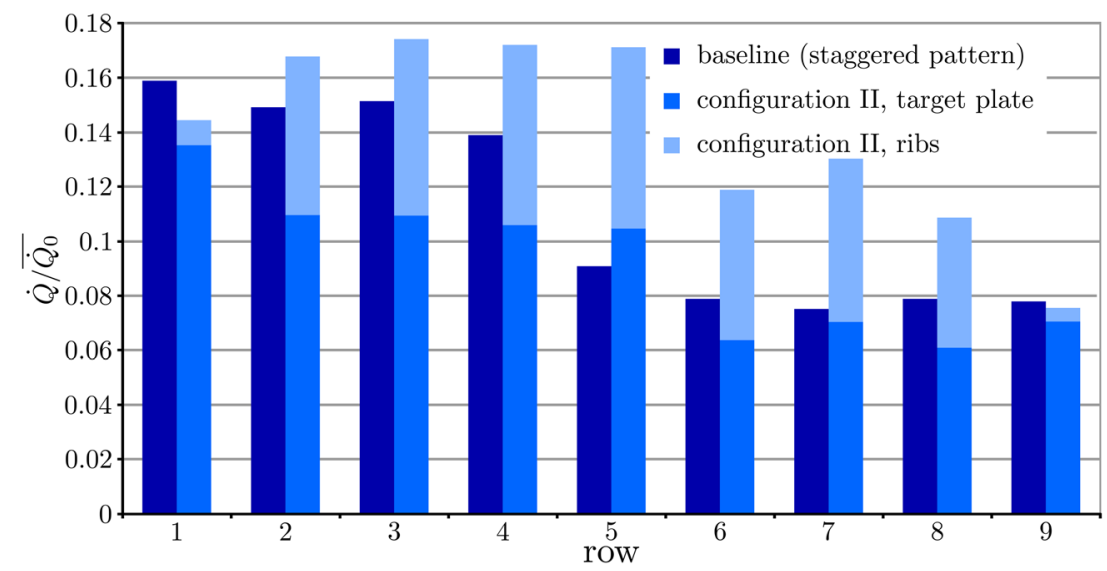

Fig. 16 Contribution of the individual surfaces to the total amount of transferred heat flux for configuration II and unribbed counterpart

taken from the CFD computations with integration of $\dot{Q}$ over all heat transfer surfaces including the rib elements.

In the up- and mid-section of the array, both configurations showed a moderate improvement compared to the unribbed target plate. Significant changes were, however, noted from row 5 on, where configuration II resulted in a heat transfer intensification between $20 \%$ and $50 \%$. Although the overall results of configuration I were not satisfying, an interesting finding is its obvious insensitivity to the degree of cross-flow, which is a fact that could be worth reconsideration in future optimizations.

The contribution of the individual surfaces, i.e., target plate and ribs, to the total amount of transferred heat flux is visualized in Figs. 15 and 16 for the two configurations and their unribbed counterparts, respectively. Again, the form of row-wise averaged quantities is chosen. All values have been referenced to the total amount of transferred heat flux of the respective unribbed configuration, $\dot{Q}_{0}$. Here, one can clearly see how the performance of the target plate is reduced in the ribbed case (due to the reduced area taking part in the heat transfer). However, this effect is compensated by the rib surfaces. This information may serve as basis for future optimization, e.g., regarding minimum rib size or rib footprint on the target plate.

The above results are summarized in Table 4 in form of total area averaged heat transfer ratios. Comparing the Nusselt number enhancement from experiments with the values obtained from CFD, one can also see how important it is to include all surfaces of the roughness elements in the data analysis. As outlined earlier, measurements were restricted to the areas on the target plate. This emphasizes how CFD can feature significant advantages with
Table 4 Total average heat transfer enhancement and pressure loss for configurations I and II

\begin{tabular}{lcc}
\hline \hline & Configuration I & Configuration II \\
\hline$\left(\overline{N u} / \overline{N u_{0}}\right)_{\text {CFD }, C V}$ & 1.01 & 1.03 \\
$\left(\overline{N u} / \overline{N u_{0}}\right)_{\exp }$ & 1.00 & 1.06 \\
$\left(\overline{\dot{Q}} / \overline{\dot{Q}_{0}}\right)_{\text {CFD }, C V}$ & 1.36 & 1.48 \\
$\left(\overline{C_{D}} / \overline{C_{D, 0}}\right)_{\exp }$ & 0.90 & 0.89 \\
\hline \hline
\end{tabular}

regards to the comprehension of these surfaces for which experimental techniques are often extremely costly if not impossible [45]. It suggests further that CFD may be used, in general, as a complement to measurements whenever ribbed surfaces are to be investigated. As the above results have shown, it is not advisable to simply neglect these in the overall validation of the thermal performance.

Regarding the pressure loss, an interesting result was that the roughness elements did not result in an increased pressure drop for the system. It explains when considering that there exist two main contributors to the total pressure drop: On the one hand, there is the pressure drop caused by the impingement of the jets onto the target plate. On the other hand, the interaction of the cross-flow with the jet flow causes increased mixing and turbulence, which then results in a loss of total pressure as well. In the present case, the rib elements helped to reduce the second mechanism due to their specific 
positioning. These trends were in agreement with the findings of other investigations $[12,17,18]$.

\section{Conclusions}

In the present work, heat transfer characteristics within arrays of impinging jets with rib-roughened target surfaces were investigated. Two configurations were tested: One with an inline arrangement of jets with ribs oriented perpendicular to the direction of cross-flow and one with a staggered arrangement of jets and ribs aligned with the direction of cross-flow. Experiments and CFD simulations were carried out for both configurations. Comparison of the results showed a reasonable degree of accuracy that can be achieved by the heat transfer predictions. Since the computations were defined as full representations of the experimental tests, the results represent current state-of-the-art in CFD, for the solver and turbulence model used. High accuracy is, however, achievable only for average quantities. For example, differences in local values may exceed $50 \%$, whereas for average values, an accuracy of around $10 \%$ is feasible. CFD offers a significant advantage in accounting for effects that are difficult to measure. This mainly relates to the heat transfer on the element surfaces. The present analysis has shown that these effects can become important for rib-roughened surfaces. It is equally important to compare such configurations by the total amount of transferred heat flux, given its knowledge on all surfaces, rather than by dimensionless quantities. This is due to the latter not accounting for the effect of area enlargement which can become significant depending on the geometry. This emphasizes that CFD heat transfer predictions can be worth considering for the prediction of jet impingement heat transfer in complex systems, but an a priori estimate on the accuracy is required.

\section{Acknowledgment}

The financial support for this work by the Friedrich and Elisabeth Boysen Foundation is highly acknowledged.

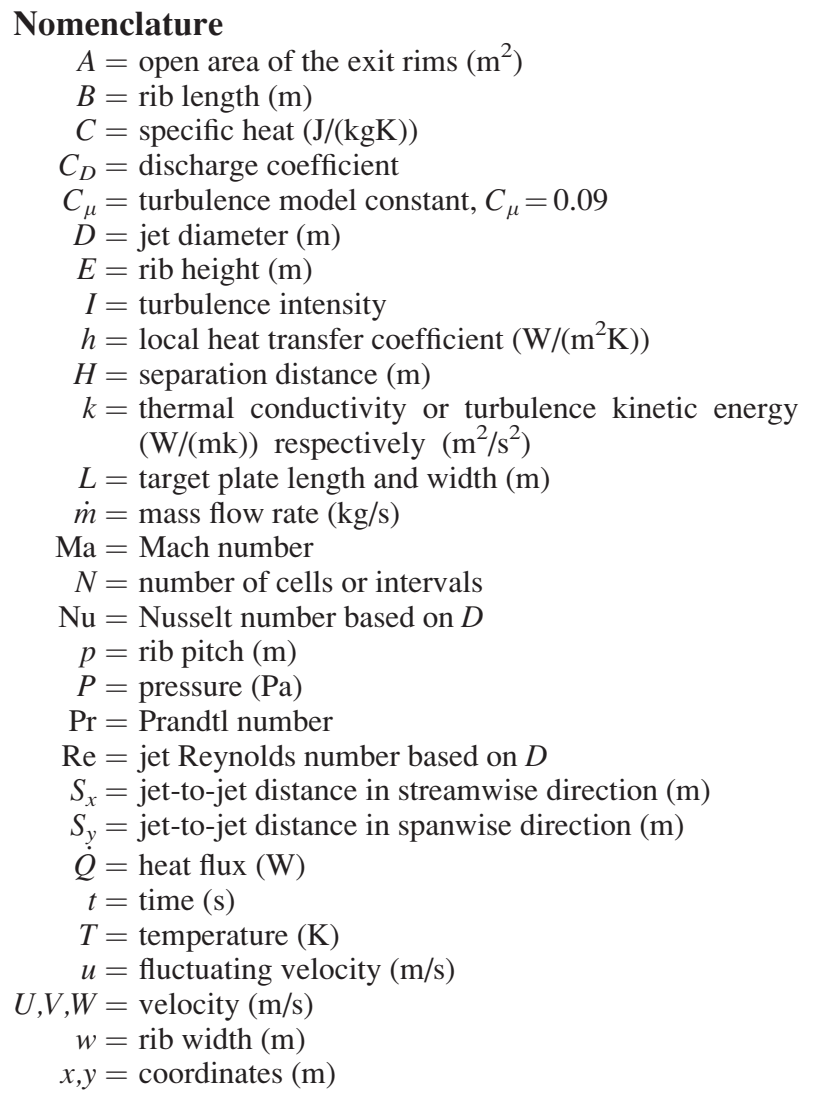

\section{Greek Symbols}

$\alpha=$ thermal diffusivity $\left(\mathrm{J} /\left(\mathrm{m}^{3} \mathrm{~K}\right)\right)$

$\varepsilon=$ dissipation rate $\left(\mathrm{m}^{2} / \mathrm{s}^{3}\right)$

$\nu=$ kinematic viscosity (Pa s)

$\nu_{t}=$ eddy-viscosity (Pa s)

$\rho=$ density $\left(\mathrm{kg} / \mathrm{m}^{3}\right)$

$\tau=$ shear $\left(\mathrm{N} / \mathrm{m}^{2}\right)$

$\Theta=$ temperature ratio

\section{Subscripts}

$0=$ initial condition or flat plate reference

$1=$ index of first cell off the wall

$B=$ bulk

$i=$ index

$t=$ turbulent

$w=$ wall

\section{Superscripts}

$+=$ dimensionless distance

\section{References}

[1] Schulz, A., 2001, "Combustor Liner Cooling Technology in Scope of Reduced Pollutant Formation and Rising Thermal Efficiencies," Ann. N.Y. Acad. Sci., 934(1), pp. 135-146.

[2] Florschuetz, L. W., Truman, C., and Metzger, D. E., 1981, "Streamwise Flow and Heat Transfer Distributions for Jet Array Impingement With Crossflow," ASME Trans. J. Heat Transfer, 103, pp. 337-342.

[3] Martin, H., 1977, Heat and Mass Transfer Between Impinging Gas Jets and Solid Surfaces (Advances in Heat Transfer), Vol. 13, Academic Press, New York, pp. 1-60.

[4] Polat, S., Huang, B., Mujumdar, A. S., and Douglas, W. J. M., 1989, "Numerical Flow and Heat Transfer Under Impinging Jets: A Review," Annu. Rev. Heat Transfer, 2(2), pp. 157-197. Available at: http://www.dl.begellhouse. com/journals/5756967540dd1b03,269acad40eb7da69,0b415dbf7639edd8.html

[5] Han, B., and Goldstein, R. J., 2001, "Jet-Impingement Heat Transfer in Gas Turbine Systems,” Ann. N.Y. Acad. Sci., 934(1), pp. 147-161.

[6] Viskanta, R., 1993, "Heat Transfer to Impinging Isothermal Gas and Flame Jets," Exp. Therm. Fluid Sci., 6(2), pp. 111-134.

[7] Weigand, B., and Spring, S., 2011, "Multiple Jet Impingement-A Review," Heat Transfer Res., 42(2), pp. 101-142.

[8] Metzger, D. E., Florschuetz, L. W., Takeuchi, D. I., Behee, R. D., and Berry, R. A., 1979, "Heat Transfer Characteristics for Inline and Staggered Arrays of Circular Jets With Crossflow of Spent Air," ASME Trans. J. Heat Transfer, 101, pp. 526-531.

[9] Florschuetz, L. W., Berry, R. A., and Metzger, D. E., 1980, "Periodic Streamwise Variations of Heat Transfer Coefficients for Inline and Staggered Arrays of Circular Jets With Crossflow of Spent Air," ASME Trans. J. Heat Transfer, 102, pp. 132-137.

[10] Obot, N. T., and Trabold, T. A., 1987, "Impingement Heat Transfer Within Arrays of Circular Jets: Part 1-Effects of Minimum, Intermediate, and Complete Crossflow for Small and Large Spacings," ASME Trans. J. Heat Transfer, 109, pp. 872-879.

[11] Xing, Y., Spring, S., and Weigand, B., 2010, "Experimental and Numerical Investigation of Heat Transfer Characteristics of Inline and Staggered Arrays of Impinging Jets," ASME Trans. J. Heat Transfer, 132(9), p. 092201.

[12] Annerfeldt, M., Persson, L., and Torisson, T., 2001, "Experimental Investigation of Impingement Cooling With Turbulators or Surface Enlarging Elements," Proceedings of ASME Turboe Expo 2001, New Orleans, LA, Jun. 4-7, Paper No. 2001-GT-0149.

[13] Trabold, T. A., and Obot, N. T, 1987, "Impingement Heat Transfer Within Arrays of Circular Jets, Part II: Effects of Crossflow in the Presence of Roughness Elements," Proceedings of the International Gas Turbine and Aeroengine Congress and Exhibition, Anaheim, CA, May 31-Jun. 4, Paper No. 87-GT-200.

[14] Chang, H., Zhang, D., and Huang, T., 1997, "Impingement Heat Transfer From Rib Roughened Surface Within Arrays of Circular Jet: The Effect of the Relative Position of the Jet Hole to the Ribs," Proceedings of the International Gas Turbine and Aeroengine Congress and Exhibition, Orlando, FL, Jun. 2-5, Paper No. 97-GT-331.

[15] Chang, H., Zhang, J., and Huang, T., 1998, "Experimental Investigation on Impingement Heat Transfer From Rib Roughened Surface Within Arrays of Circular Jet: Effect of Geometric Parameters," Proceedings of the International Gas Turbine and Aeroengine Congress and Exhibition, Stockholm, Sweden, Jun. 2-5, Paper No. 98-GT-208.

[16] Chang, H., Zhang, J., and Huang, T., 2000, "Experimental Investigation on Impingement Heat Transfer From Rib Roughened Surface Within Arrays of Circular Jets: Correlation," Proceedings of ASME Turbo Expo 2000, Munich, Germany, May 8-11, Paper No. 2000-GT-220. 
[17] Andrews, G., Abdul Hussain, R., and Mkpadi, M., 2003, "Enhanced Impingement Heat Transfer: Comparison of Co-Flow and Cross-Flow With Rib Turbulators," Proceedings of IGTC2003, Paper No. IGTC2003 Tokyo TS-075.

[18] Andrews, G., Hussain, R., and Mkpadi, M., 2006, "Enhanced Impingement Heat Transfer: The Influence of Impingement $\mathrm{x} / \mathrm{d}$ for Interrupted Rib Obstacles (Rectangular Pin Fins)," J. Turbomach., 128, pp. 321-331.

[19] Nam, Y., Rhee, D., and Cho, H., 2003, "Heat Transfer in Impingement/ Effusion Cooling System With Rib Turbulators," Proceedings of the International Gas Turbine Congress 2003 Tokyo, Nov. 2-7, Paper No. IGTC2003 Tokyo TS-076.

[20] Son, C., Ireland, P., and Gillespie, D., 2005, "The Effect of Roughness Element Fillet Radii on the Heat Transfer Enhancement in an Impingement Cooling System." Proceedings of GT2005 ASME Turbo Expo 2005: Power for Land, Sea and Air, Reno-Tahoe, NV, Jun. 6-9, Paper No. GT2005-68186.

[21] Son, C., Dailey, G., Ireland, P., and Gillespie, D., 2005, “An Investigation of the Application of Roughness Elements to Enhance Heat Transfer in an Impingement Cooling System," Proceedings of GT2005 ASME Turbo Expo 2005: Power for Land, Sea and Air, Reno-Tahoe, NV, Jun. 6-9, Paper No. GT2005-68504

[22] Yan, W., Liu, H., Soong, C., and Yang, W., 2005, "Experimental Study of Impinging Heat Transfer Along Rib-Roughened Walls by Using Transient Liquid Crystal Technique,” Int. J. Heat Mass Transfer, 48(12), pp. 2420-2428.

[23] Yan, W., and Mei, S., 2006, "Measurement of Detailed Heat Transfer Along Rib-Roughened Surface Under Arrays of Impinging Elliptic Jets," Int. J. Heat Mass Transfer, 49(1-2), pp. 159-170.

[24] Zuckerman, N., and Lior, N., 2005, "Impingement Heat Transfer: Correlations and Numerical Modeling," ASME Trans. J. Heat Transfer, 127, pp. 544-552.

[25] Coussirat, M., Van Beeck, J., Mestres, M., Egusguiza, M., Buchlin, J.-M., an Escaler, X., 2005, "Computational Fluid Dynamics Modeling of Impinging Gas-Jet Systems: I. Assessment of Eddy Viscosity Models," ASME J. Fluids Eng., 127, pp. 691-703.

[26] Spring, S., and Weigand, B., 2010, "Jet Impingement Heat Transfer," Internal Cooling in Turbomachinery (VKI Lecture Series 2010-05), von Karman Institute for Fluid Dynamics, Rhode-St-Genèse, Belgium.

[27] Jia, R., Rokni, M., and Sunden, B., 2003, "Numerical Investigation of Impingement Cooling in Ribbed Ducts Due to Jet Arrays," J. Enhanced Heat Transfer, 10, pp. $243-256$

[28] Xing, Y., and Weigand, B., 2010, "Experimental Investigation on Staggered Impingement Heat Transfer on a Rib Roughened Plate With Different Crossflow Schemes," Proceedings of ASME Turbo Expo 2010: Power for Land, Sea and Air, GT2010, Glasgow, UK, Jun. 14-18, Paper No. GT2010-22043.

[29] Spring, S., Lauffer, D., Weigand, B., and Hase, M., 2010, "Experimental and Numerical Investigation of Impingement Cooling in a Combustor Liner Heat Shield," J. Turbomach., 132(1), p. 011003.
[30] Poser, R, von Wolfersdorf, J., and Lutum, E., 2007, "Advanced Evaluation of Transient Heat Transfer Experiments Using Thermochromic Liquid Crystals," Proc. Inst. Mech. Eng., Part A, 221(6), pp. 793-801.

[31] Ireland, P. T., and Jones, T. V., 2000, "Liquid Crystal Measurements of Heat Transfer and Surface Shear Stress," Meas. Sci. Technol., 11(7), pp. 969-986.

[32] Wagner, G., Kotulla, M., Ott, P., Weigand, B., and von Wolfersdorf, J., 2004, "The Transient Liquid Crystal Technique: Influence of Surface Curvature and Finite Wall Thickness," Proceedings of ASME Turbo Expo 2004, Power for Land, Sea, and Air, Vienna, Austria, Jun. 14-17.

[33] Kays, W., Crawford, M., and Weigand, B., 2004, Corrective Heat and Mass Transfer, Vol. 4, McGraw-Hill, New York.

[34] Kline, S. J., and McClintock, F. A., 1953, "Describing Uncertainties in SingleSample Experiments," J. Mech. Eng., 75, pp. 3-8. Available at: http://www. mendeley.com/research/describing-uncertainties-in-singlesample-experiments

[35] Yan, Y., and Owen, J. M., 2002. "Uncertainties in Transient Heat Transfer Measurements With Liquid Crystal,” Int. J. Heat Fluid Flow, 23, pp. 29-35.

[36] Kingsley-Rowe, J. R., Lock, G. D., and Owen, J. M., 2005, "Transient Heat Transfer Measurements Using Thermochromic Liquid Crystal: LateralConduction Error," Int. J. Heat Fluid Flow, 26, pp. 256-263.

[37] Menter, F., 1994, "Two-Equation Eddy-Viscosity Turbulence Models for Engineering Applications," AIAA J., 32(8), pp. 1598-1605.

[38] Celik, I. B., Ghia, U., Roache, P. J., Freitas, C. J., Coleman, H., and Raad, P. E., 2008, "Procedure for Estimation and Reporting of Uncertainty Due to Discretization in CFD Applications," ASME J. Fluids Eng., 130, p. 0708001.

[39] Roache, P. J., 1994, "A Method for Uniform Reporting of Grid Refinement Studies," ASME J. Fluids Eng., 116, pp. 405-413.

[40] Cooper, D., Jackson, D., Launder, B., and Liao, G., 1993, "Impinging Jet Studies for Turbulence Model Assessment, Part I: Flow-Field Experiments," Int. J. Heat Mass Transfer, 36, pp. 2675-2684.

[41] Patankar, S. V., Pratab, V. S., and Spalding, D. B., 1975, "Prediction of Turbulent Flow in Curved Pipes," J. Fluid Mech., 67(3), pp. 583-595.

[42] Pope, S. B., 1978, "An Explanation of the Turbulent Round-Jet/Plane-Jet Anomaly," AIAA J., 16(3), pp. 279-281.

[43] Bernard, A., Brizzi, L.-E., and Bousgarbies, J.-L., 1999, "Study of Several Jets Impinging on a Plane Wall: Visualizations and Laser Velocimetry Investigations," ASME J. Fluids Eng., 121(4), pp. 808-812.

[44] Chung, Y., Luo, K., and Sandham, N., 2002, "Numerical Study of Momentum and Heat Transfer in Unsteady Impinging Jets," Int. J. Heat Fluid Flow, 23(5), pp. $592-600$

[45] Coletti, F., and Arts, T., 2010, "Experimental Study of Conjugate Heat Transfer in a Rib-Roughened Trailing Edge Cooling Channel With Crossing-Jets," Internal Cooling in Turbomachinery (VKI Lecture Series 2010-05), von Karman Institute for Fluid Dynamics, Rhode-St-Genèse, Belgium. 